\title{
MCNP Simulation of Physics Parameters of Dispersion Fuels for Conversion of NIRR-1 to LEU
}

\author{
Kola Ibikunle1, Umar Sadiq², Yakubu Viva Ibrahim², Sunday Adesunloye Jonah²* \\ ${ }^{1}$ Department of Physics, Ahmadu Bello University, Zaria, Nigeria \\ ${ }^{2}$ Centre for Energy Research and Training, Ahmadu Bello University, Zaria, Nigeria \\ Email: *jonahsa2001@yahoo.com
}

How to cite this paper: Ibikunle, K., Sadiq, U., Ibrahim, Y.V. and Jonah, S.A. (2018) MCNP Simulation of Physics Parameters of Dispersion Fuels for Conversion of NIRR-1 to LEU. World Journal of Nuclear Science and Technology, 8, 23-29.

https://doi.org/10.4236/wjnst.2018.82003

Received: January 3, 2018

Accepted: March 30, 2018

Published: April 2, 2018

Copyright $\odot 2018$ by authors and Scientific Research Publishing Inc. This work is licensed under the Creative Commons Attribution International License (CC BY 4.0).

http://creativecommons.org/licenses/by/4.0/

\begin{abstract}
The Nigeria Research Reactor-1 (NIRR-1) is one of the Commercial Miniature Neutron Source Reactors (MNSRs) sited outside China and scheduled for conversion under the auspices of Reduced Enrichment for Research and Test Reactors (RERTR) program. Since 2006, the reduction in the fuel enrichment of MSNR facilities from greater than $90 \%$ HEU cores to less than 20\% LEU cores has been embarked upon. Consequently in this work, the physics parameters of three dispersion LEU fuels, which include $\mathrm{U}_{3} \mathrm{Si}, \mathrm{U}_{3} \mathrm{Si}_{2}$, and $\mathrm{U}_{9} \mathrm{Mo}$ enriched to $19.75 \%$ were determined by the MCNP code to investigate their suitability for the conversion of NIRR-1 to LEU. The following reactor core physics parameters were computed for the LEU fuel options: clean cold core excess reactivity $\left(\rho_{e x}\right)$, control rod (CR) worth, shut down margin (SDM), neutron flux distributions in the irradiation channels and kinetics data (i.e. effective delayed neutron fraction, $\beta_{\text {eff }}$ and prompt neutron lifetime, $l_{f}$ ). Results are compared with experimental and calculated data of the current HEU core and indicate that it would be feasible to use any of the LEU options for the conversion of commercial MNSR in general and NIRR-1 in particular from HEU to LEU.
\end{abstract}

\section{Keywords}

Neutronics Data, HEU to LEU Conversion, MNS Reactors, Dispersion Fuels, MCNP

\section{Introduction}

The Nigeria Research Reactor-1 (NIRR-1) is one of the five commercial MNSR 
facilities designed by China Institute of Atomic Energy (CIAE) that are sited outside China. First criticality was achieved on 3 February 2004 and has been operated safely [1] [2] [3]. It is specifically designed for use in neutron activation analysis (NAA) and limited radioisotope production. Neutronics calculations were first performed for the current HEU core in order to validate the developed MNCP model and the computational methods [4]. Under the aegis of the International Atomic Energy Agency's (IAEA) Coordinated Research Project (CRP) from 2006 to 2012, a neutronics feasibility study for LEU conversion of the reactor was performed [5]. The major outcome of the CRP is that $\mathrm{UO}_{2}$ pellets enriched to $12.5 \%$ would be used for the conversion of commercial MNSR facilities and the prototype in China. Similar investigations with the $\mathrm{UO}_{2}$ pellets with enrichment of $12 \%$ and $12.5 \%$ have been reported for NIRR-1 in particular and MNSR in general [6] [7]. A detailed description of NIRR-1 and measured core physics data can be found in the final SAR [1]. The objective of this study is to further identify other qualified LEU fuels that can match the HEU core in terms of core physics parameters and magnitudes of the neutron flux in the irradiation channels. In a previous work, Matos et al., 2005 [8] investigated the use of some qualified LEU fuels that can be used for the conversion of commercial MNSR. The results they obtained were found to be outside the recommended data for the cold core excess reactivity. Therefore, three of the dispersion fuels, which include $\mathrm{U}_{3} \mathrm{Si}, \mathrm{U}_{3} \mathrm{Si}_{2}$, and $\mathrm{U} 9-\mathrm{Mo}$ enriched to $19.75 \%$ were re-investigated in this work vis-à-vis their core physics parameters.

\section{Materials and Method}

Three qualified LEU fuels were used to substitute the HEU in the original input deck developed for NIRR-1. An MCNP diagram of the established HEU model of NIRR-1 is depicted in Figure 1. Since NIRR-1 is specifically designed for NAA, conversion to LEU should not compromise its utilization capacity, especially with respect to the neutron flux and spectrum distributions. Consequently, the methodology and MCNP model that were used in the neutronics analysis of the HEU were also used to search for the LEU options. The first step in the conversion study was to determine the impact of replacing HEU fuel with LEU in the same core configuration. The three potential dispersion LEU fuels are $\mathrm{U}_{3} \mathrm{Si}$, $\mathrm{U}_{3} \mathrm{Si}_{2}$, and $\mathrm{U}_{9} \mathrm{Mo}$ enriched to $19.75 \%$. For these three options, the core configuration of 347 pins is maintained and the fuel pin outer diameter is also fixed at $5.5 \mathrm{~mm}$. However, the volume fraction of the dispersed phase was varied for each of the fuels such that the core excess reactivity is kept the same $(\sim 4.7 \mathrm{mk})$ as the HEU reference core. The parameters of the three LEU fuel options considered in this study are listed in Table 1.

In the MCNP model, the HEU fueled core of NIRR-1 was created in a three-dimensional, Cartesian coordinate system. The input deck was constructed using detailed engineering drawings of the reactor obtained from the SAR [1]. The deck was run as a KCODE source problem for criticality calculations using 


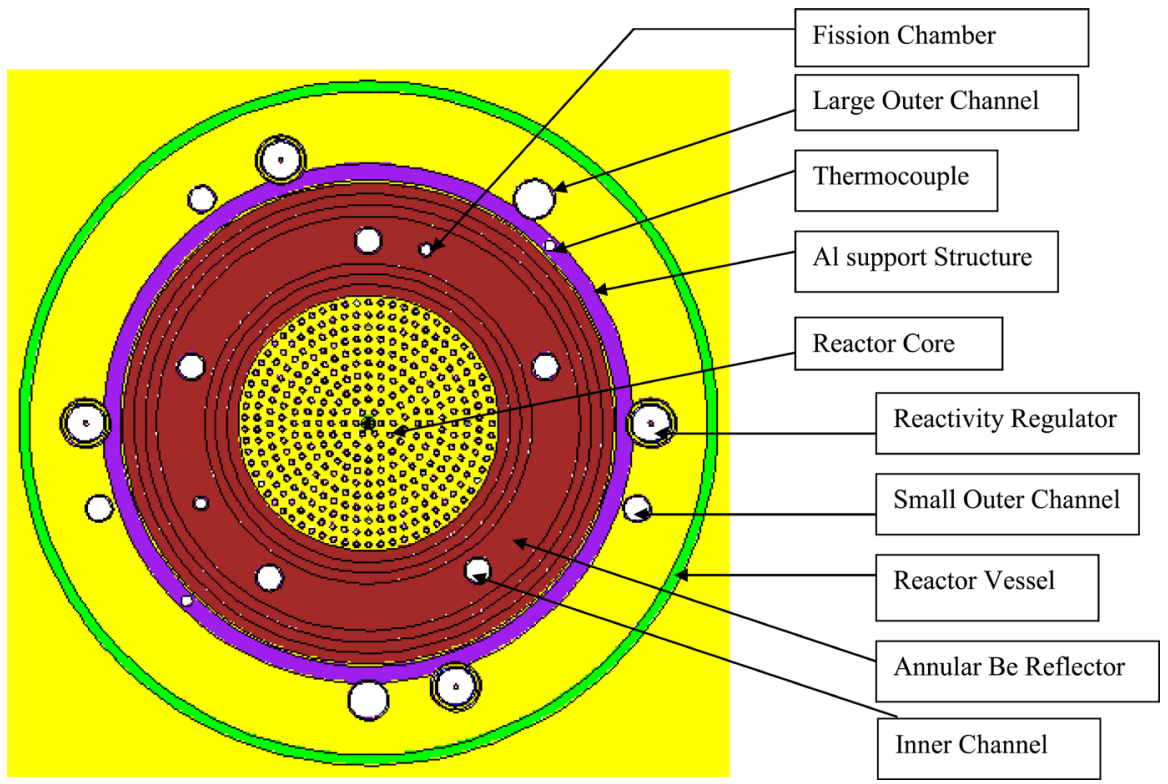

Figure 1. An MCNP diagram of NIRR-1 core in the x-y plane.

Table 1. Design data of the HEU and LEU fuel options.

\begin{tabular}{cccccc}
\hline & $\begin{array}{c}\text { Fuel Type/ } \\
\text { Enrichment } \%\end{array}$ & $\begin{array}{c}\text { Density of } \\
\text { Meat/U }(\mathrm{g} / \mathrm{cc})\end{array}$ & $\begin{array}{c}\text { Meat diameter } \\
(\mathrm{mm})\end{array}$ & $\begin{array}{c}\text { Clad material/ } \\
\text { thickness }(\mathrm{mm})\end{array}$ & $\begin{array}{c}\text { No of fuel } \\
\text { pins }\end{array}$ \\
\hline 1 & $\mathrm{HEU}-\mathrm{HAl}_{4} / 90.2 \%$ & $3.456 / 0.92$ & 4.30 & $\mathrm{Al} / 0.60$ & 347 \\
2 & $\mathrm{LEU}-\mathrm{U}_{3} \mathrm{Si} / 19.75 \%$ & $7.394 / 5.49$ & 4.30 & $\mathrm{Al} / 0.60$ & 347 \\
3 & $\mathrm{LEU}-\mathrm{U}_{3} \mathrm{Si}_{2} / 19.75 \%$ & $6.409 / 4.42$ & 4.74 & $\mathrm{Al} / 0.38$ & 347 \\
4 & $\mathrm{LEU}-\mathrm{U}_{9} \mathrm{Mo} / 19.75 \%$ & $8.210 / 5.95$ & 4.30 & $\mathrm{Al} / 0.60$ & 347 \\
\hline
\end{tabular}

the MCNP code version 5 - 1.6.

With the increasing availability of affordable computing devices and taking advantage of parallel features of the MCNP code to speed up the Monte Carlo simulations, a computing cluster made up workstations running Microsoft Windows \& Linux (Cent OS) operating systems was set up for this work.

On the windows platform, the default binaries supplied with the code was installed, while for the Linux environment, the binaries were built using the Intel Fortran complier 12.1 .5 version. MPICH2 version $1.4 .1 \mathrm{p} 1$ was chosen as the parallel communication software. MPICH is a high performance portable implementation of the Message Passing Interface standards whose software is distributed under the BSD license and is available on common platforms such as Windows, Linux and Mac OS/X. An IP network is configured for layer 3 communications between all the nodes participating in the calculations and the MCNP jobs are assigned based on each computing node's capabilities such as the processor speed and number of cores per processor. Only the master node needs to have the complete MCNP code with the data library installed, while the platform specific binaries are installed on the secondary nodes.

Several runs were made with $1 / 2$ a million particles in 400 cycles. Tallies were 
constructed for the calculation of axial neutron flux distributions in the fuel pins, fission chambers irradiation channels and the slant tube. Similarly, tally cards for power distributions in the different fuel pins and the 10 fuel rings were added. The following neutronics data were calculated and they include clean cold core excess reactivity $\left(\rho_{e x}\right)$, control rod (CR) worth, shut down margin $(\mathrm{SDM})$, neutron flux distributions in the irradiation channels and kinetics data (i.e. effective delayed neutron fraction, $\beta_{\text {eff }}$ and prompt neutron lifetime, $l_{f}$ ). Results obtained were benchmarked by calculated data for the HEU and measured data in the final SAR

\section{Results and Discussion}

Results of the core physics neutronics data obtained in this work are compared with calculated and measured data for the current HEU core in Table 2. The cold core excess reactivity determined for the HEU core during the on-site start-up and power rising experiment was $4.97 \mathrm{mk}$. In order to obtain the licensed value of 3 - $4 \mathrm{mk}$ for MNSR, a Cd absorber with reactivity worth of -1.2 $\mathrm{mk}$ was inserted into an unconnected inner irradiation channel. The calculated result obtained for the HEU core was found to be $4.73 \mathrm{mk}$ and was used as the benchmark for the design of the three LEU fuels considered in this work. As can be seen in Table 2 , the $k_{\text {eff }}$ clean cold core excess reactivity $\left(\rho_{e x}\right)$, control rod (CR) worth and the shutdown margin (SDM) compare well with data for the HEU core.

Furthermore, magnitudes of the thermal, epithermal and fast neutron flux in the irradiation channels for the current HEU core and the LEU options are compared in Table 3.

The calculated thermal neutron flux value of $1.19 \times 10^{12} \mathrm{n} / \mathrm{cm}^{2}$.s for the present HEU core at the inner irradiation site is in close agreement with the nominal value of $1.0 \times 10^{12} \mathrm{n} / \mathrm{cm}^{2}$.s typically displayed on the control console during the steady state operation at full power (i.e. $31 \mathrm{~kW}$ ). In the case of the outer

Table 2. Measured and calculated core physics data of reference HEU and candidates LEU fuels.

\begin{tabular}{|c|c|c|c|c|c|}
\hline & $\begin{array}{l}\text { HEU-UAl }{ }_{4}-347 \\
90.2 \% \text { Measured }\end{array}$ & 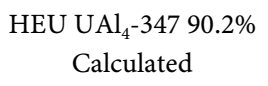 & $\begin{array}{c}\text { LEU-U } \mathrm{U}_{3} \mathrm{Si} 19.75 \%-347 \\
\text { Calculated }\end{array}$ & $\begin{array}{c}\text { LEU-U } \mathrm{U}_{3} \mathrm{Si}_{2} 19.75 \%-347 \\
\text { Calculated }\end{array}$ & $\begin{array}{c}\text { LEU-U } \text { U }_{9} \text { Mo } 19.75 \%-347 \\
\text { Calculated }\end{array}$ \\
\hline$k_{\text {eff }}$ rod out & & $1.00475 \pm 0.00006$ & $1.00472 \pm 0.00006$ & $1.00478 \pm 0.00006$ & $1.00482 \pm 0.00006$ \\
\hline$k_{\text {eff }}$ rod in & & $0.99715 \pm 0.00006$ & $0.99799 \pm 0.00006$ & $0.99807 \pm 0.00006$ & $0.99829 \pm 0.00006$ \\
\hline $\begin{array}{c}\text { Clean core excess } \\
\rho_{e x}=\frac{\left(k_{\text {eff }}-1\right)}{k_{\text {eff }}} \text { reactivity, } \\
(\mathrm{mk})\end{array}$ & 4.97 & 4.73 & 4.70 & 4.76 & 4.80 \\
\hline $\begin{array}{l}\text { Control rod worth (mk) } \\
\qquad \rho_{w}=\frac{\left(k_{\text {eff }}^{\text {out }}-k_{\text {eff }}^{\text {in }}\right)}{\left(k_{\text {eff }}^{\text {out }} k_{\text {eff }}^{\text {in }}\right)}\end{array}$ & 7 & 7.59 & 6.71 & 6.69 & 6.51 \\
\hline $\begin{array}{l}\text { Shut Down Margin (mk) } \\
\qquad \rho_{\mathrm{w}}-\rho_{e x}\end{array}$ & 2.03 & 2.86 & 2.01 & 1.93 & 1.71 \\
\hline
\end{tabular}


irradiation channel, the calculated thermal neutron flux is $6.77 \times 10^{11} \mathrm{n} / \mathrm{cm}^{2} \cdot \mathrm{s}$ representing approximately $50 \%$ of the value obtained in the inner channel; this is in agreement with the manufacturer's data. As shown in Table 3, there is a reduction of an average of approximately $10 \%$ in the magnitude of thermal neutron flux in the irradiation channels for the three LEU fuels in comparison with the HEU. Consequently, for an LEU fueled core, the reactor power level would need to be raised from the current value of $31 \mathrm{~kW}$ to $34 \mathrm{~kW}$ in order to match the nominal flux level (i.e. of $1 \times 10^{12} \mathrm{n} / \mathrm{cm}^{2} \cdot s$ in the inner channel) for NIRR-1 thus ensuring that NAA utilization for which MNSR facilities were specifically designed is not compromised.

In order to further assess the suitability of the three fuels for NIRR-1 conversion, kinetics parameters of the fuels used in this work are compared with those of the HEU core and the results are presented in Table 4. The kinetics parameters of the fuel options were calculated using the adjoint method (KOPTS) and by turning "on" and "off" the physics card (TOTNU) option. The adjoint method derives from the reactor point kinetic equation and employs an enhanced feature of the MNCP in version 5 - 1.6 to calculate the kinetics parameters. For the effective delayed neutron fraction, $\beta_{\text {eff }}$ the calculation was performed using the KOPTS and TOTNU card options, while the prompt neutron lifetime, $l_{f}$ of the fuel options were calculated using the adjoint method.

Results show that the $\beta_{\text {eff }}$ for the three fuels compare well with calculated and measured data for the current HEU core. Similarly, the $I_{f}$ for the three fuels

Table 3. Calculated thermal, epithermal and fast flux in the inner and outer irradiation sites.

\begin{tabular}{|c|c|c|c|c|c|c|}
\hline \multirow[t]{2}{*}{ Fuel type } & \multicolumn{2}{|c|}{$\begin{array}{c}\text { Thermal } \\
(0-0.625 \mathrm{eV}) \mathrm{n} / \mathrm{cm}^{2} \cdot \mathrm{s} \times 10^{11}\end{array}$} & \multicolumn{2}{|c|}{$\begin{array}{c}\text { Epithermal } \\
(0.625 \mathrm{eV}-0.825 \mathrm{MeV}) \\
\mathrm{n} / \mathrm{cm}^{2} \cdot \mathrm{s} \times 10^{11}\end{array}$} & \multicolumn{2}{|c|}{$\begin{array}{c}\text { Fast } \\
(0.825 \mathrm{MeV}-20 \mathrm{MeV}) \\
\mathrm{n} / \mathrm{cm}^{2} \cdot \mathrm{s} \times 10^{11}\end{array}$} \\
\hline & Inner & Outer & Inner & Outer & Inner & Outer \\
\hline HEU-UAl ${ }_{4}$ & $11.91 \pm 0.01$ & $6.77 \pm 0.01$ & $13.39 \pm 0.01$ & $1.84 \pm 0.01$ & $2.77 \pm 0.01$ & $0.368 \pm 0.003$ \\
\hline LEU-U $\mathrm{U}_{3} \mathrm{Si}$ & $11.06 \pm 0.01$ & $6.18 \pm 0.01$ & $13.23 \pm 0.01$ & $1.80 \pm 0.01$ & $2.75 \pm 0.01$ & $0.348 \pm 0.003$ \\
\hline LEU-U $\mathrm{U}_{3} \mathrm{Si}_{2}$ & $11.05 \pm 0.01$ & $6.54 \pm 0.01$ & $13.25 \pm 0.01$ & $1.89 \pm 0.01$ & $2.74 \pm 0.01$ & $0.368 \pm 0.003$ \\
\hline LEU-U ${ }_{9}-\mathrm{Mo}$ & $10.46 \pm 0.01$ & $6.26 \pm 0.01$ & $12.82 \pm 0.01$ & $1.83 \pm 0.01$ & $2.65 \pm 0.01$ & $0.353 \pm 0.003$ \\
\hline
\end{tabular}

Table 4. Comparison of kinetics data of LEU fuels with data for the HEU core.

\begin{tabular}{cccccc}
\hline $\begin{array}{c}\text { Kinetic } \\
\text { Parameters }\end{array}$ & $\begin{array}{c}\text { CIAE } \\
\text { (quoted } \\
\text { values })\end{array}$ & $\begin{array}{c}\text { HEU 90\% } \\
(347)\end{array}$ & $\begin{array}{c}\text { LEU U }_{3} \mathrm{Si} \mathrm{19.75 \%} \\
(347)\end{array}$ & $\begin{array}{c}\text { LEU U }_{3} \mathrm{Si}_{2} \\
19.75 \%(347)\end{array}$ & $\begin{array}{c}\text { LEU-U } \\
\text { ( Mo 19.75\% } \\
(347)\end{array}$ \\
\hline $\begin{array}{c}\beta_{\text {eff }} \\
(\mathrm{TOTNU})\end{array}$ & 0.0081 & $0.00834 \pm 0.00008$ & $0.00831 \pm 0.00008$ & $0.00841 \pm 0.00008$ & $0.00836 \pm 0.00008$ \\
$\beta_{\text {eff }}(\mathrm{KOPTS})$ & 0.0081 & $0.00849 \pm 0.00008$ & $0.00840 \pm 0.00008$ & $0.00843 \pm 0.00008$ & $0.00844 \pm 0.00008$ \\
$\begin{array}{c}l_{f}(\mathrm{KOPTS}) \\
(\mu \mathrm{s})\end{array}$ & 81.2 & $56.09 \pm 0.09$ & $50.33 \pm 0.09$ & $50.21 \pm 0.09$ & $48.71 \pm 0.09$ \\
\hline
\end{tabular}


compare well with calculated data for the HEU core but deviate from the manufacturer's value. In order to ascertain the suitability of the three LEU fuels for NIRR-1 conversion, there is a need to investigate their steady state and transients characteristics in comparison with the current HEU core. Consequently, the reactivity feedback coefficients are desirable for this endeavor and will form the basis of further investigations.

\section{Conclusions}

The physics parameters of three dispersion LEU fuels, which include $\mathrm{U}_{3} \mathrm{Si}, \mathrm{U}_{3} \mathrm{Si}_{2}$, and $\mathrm{U}_{9} \mathrm{Mo}$ enriched to $19.75 \%$ have been determined by the MCNP code in order to investigate their suitability for the conversion of NIRR-1 to LEU. Results obtained for the clean cold core excess reactivity $\left(\rho_{e x}\right)$, control rod (CR) worth and the shutdown margin (SDM) of the three LEU fuels compare well with data for the HEU core. Additionally, data for the thermal neutron flux in the irradiation channels of the dispersion fuels indicate a reduction of an average of approximately $10 \%$ in the magnitude in comparison with the HEU core. Consequently, for an LEU fueled core, the reactor power level would need to be raised from the current value of $31 \mathrm{~kW}$ to $34 \mathrm{~kW}$ in order to match the nominal flux level (i.e. of $1 \times 10^{12} \mathrm{n} / \mathrm{cm}^{2} . s$ in the inner channel). Furthermore, calculated kinetics data of the three LEU fuels indicate their suitability for NIRR-1 conversion to LEU.

\section{References}

[1] Nigeria Research Reactor-1 (NIRR-1). (2005) Final Safety Analyses Report (FSAR) CERT/NIRR1/SAR/02, CERT.

[2] Jonah, S.A., Balogun, G.I., Umar, I.M. and Mayaki, M.C. (2005) Neutron Spectrum Parameters in Irradiation Channels of the Nigeria Research Reactor-1 (NIRR-1) for the $k_{0}$-NAA Standardization Method. Journal of Radioanalytical and Nuclear Chemistry, 266, 83-88. https://doi.org/10.1007/s10967-005-0873-8

[3] Jonah, S.A., Umar, I.M., Oladipo, M.O.A., Balogun, G.I. and Adeyemo, D.J. (2006) Standardization of NIRR-1 Irradiation and Counting Facilities for Instrumental Neutron Activation Analysis. Applied Radiation and Isotopes, 64, 818-822. https://doi.org/10.1016/j.apradiso.2006.01.012

[4] Jonah, S.A., Liaw, J.R. and Matos, J.E. (2007) Monte Carlo Simulation of Core Physics Parameters of Nigerian Research Reactor-1. Annals of Nuclear Energy, 34, 953-957. https://doi.org/10.1016/j.anucene.2007.05.010

[5] Jonah, S.A. and Ibrahim, Y.V. (2016) Final Report of Analyses Performed under the IAEA CRP (NIR/13934) for the Conversion of Nigeria MNSR (NIRR-1) to LEU, 2006-2012. IAEA-TEDOC 2016. (In Press)

[6] Jonah, S.A., Ibikunle, K. and Li, Y. (2009) A Feasibility Study of LEU Enrichment Uraniumfuels for MNSR Conversion Using MCNP. Annals of Nuclear Energy, 36, 1285-1286. https://doi.org/10.1016/j.anucene.2009.05.001

[7] Li, Y., Xia, P., Zou, S., Zhan, Y., Lu, Z., Zheng, W., Shi, Y., Gao, J. and Zhou, Y. (2007) The Physics Experimental Study for the Special MNSR. The 2007 International Meeting on Reduced Enrichment for Research and Test Reactors, Prague, Czech Republic, 23-27 September 2007. 
[8] Matos, J.E. and Lell, R.M. (2005) Feasibility Study of Potential LEU Fuels for a Generic MNSR Reactor. Proceedings of 2005 International Meeting on Reduced Enrichment for Research and Test Reactors, Boston, Massachusetts, 6-10 November 2005. 